\title{
Dynamic response of a cable-stayed footbridge to high-energy mining tremors
}

\author{
Izabela Drygała ${ }^{1, *}$, Joanna M. Dulinska ${ }^{1}$, Maria Anna Polak $^{2}$, Marek Wazowski ${ }^{3}$ \\ ${ }^{1}$ Cracow University of Technology, Warszawska 24, 31-155 Krakow, Poland \\ ${ }^{2}$ University of Waterloo, 200 University Avenue West, Waterloo N2L 3G1, Canada \\ ${ }^{3}$ Aspekt Laboratorium Sp. z o.o., Chopina 96, 43-600 Jaworzno, Poland
}

\begin{abstract}
In this work an analysis of the dynamic response of a cablestayed footbridge to mining tremors typical for two main regions of mining activity in Poland, i.e. the Legnica-Glogow Copper District (LGCD) and the Upper Silesian Coal Basin (USCB) is presented. For analysis, a 3-D finite element (FE) model of the structure was created in the ABAQUS/Standard software program. As a final result, the dynamic responses of the footbridge to the typical mining tremors were delivered. For this stage, the numerical simulations were conducted with the non-uniform kinematic excitation as well as with the uniform kinematic excitation. Finally, the evaluation of two calculation approaches was also made for the studied structure.
\end{abstract}

Keywords: footbridge, dynamic analysis, seismic assessment, non-uniform ground excitations, high-energy mining tremor

\section{Introduction}

The seismic assessment of the dynamic response of civil engineering structures to mining tremors became a task of studies in Poland [1], since energy and amplitudes of vibrations caused by high-energy mining shocks are comparable with amplitudes of vibrations resulting from small earthquakes. In general, footbridges are exposed to this type dynamic loading. After the earthquake in Canterbury (New Zealand) in September 2010 it was possible to observe the shape of damages for several footbridges [2]. For seismic assessment of pedestrian bridges, it is reasonable to consider the type of their foundation, i.e. bridges are multiple-support structures $[3,4]$.

This paper presents the dynamic response of a cable-stayed footbridge to mining tremors registered in two main mining activity regions in Poland. The main objective of the study was to recognize the influence of the spatially varying ground motion to the dynamic assessment of the footbridge. The study was completed with numerical investigations. The evaluation of two calculation approaches, i.e. with uniform as well as non-uniform kinematic excitation, is also undertaken.

\footnotetext{
*Corresponding author: idrygala@pk.edu.pl
} 


\section{Non-uniform kinematic excitation}

The mathematical formulation of motion of a general multi-degree of freedom structure under kinematic loading can be expressed as follows ([4]):

$$
\left[\begin{array}{ll}
M_{s s} & M_{s g} \\
M_{g s} & M_{g g}
\end{array}\right]\left\{\begin{array}{l}
\ddot{u}_{s}^{t} \\
\ddot{u}_{g}
\end{array}\right\}+\left[\begin{array}{cc}
C_{s s} & C_{s g} \\
C_{g s} & C_{g g}
\end{array}\right]\left\{\begin{array}{l}
\dot{u}_{s}^{t} \\
\dot{u}_{g}
\end{array}\right\}+\left[\begin{array}{ll}
K_{s s} & K_{s g} \\
K_{g s} & K_{g g}
\end{array}\right]\left\{\begin{array}{c}
u_{s}^{t} \\
u_{g}
\end{array}\right\}=\left\{\begin{array}{c}
0 \\
F_{g}
\end{array}\right\}
$$

where: $s$ - degrees of freedom of the structure; $g$ - degrees of freedom of the ground; $[M]$ - a mass matrix; $[C]$ - a damping matrix; $[K]$ - a stiffness matrix; $\left\{\ddot{u}_{s}^{t}\right\}$ - vectors of total accelerations of the structure; $\left\{\dot{u}_{s}^{t}\right\}$ - vectors of total velocities of the structure; $\left\{u_{s}^{t}\right\}$-vectors of total displacements of the structure; $\left\{\ddot{u}_{g}\right\}$ - vectors of total accelerations of the ground motion; $\left\{\dot{u}_{g}\right\}$ - vectors of total velocities of the ground motion; $\left\{u_{g}\right\}$ - vectors of total displacements of the ground motion; $\left\{F_{g}\right\}$ - a vector of reaction forces. Equation (1) can be transformed into the formula:

$$
\left[M_{s s}\right]\left\{\ddot{u}_{s}^{t}\right\}+\left[C_{s s}\right]\left\{\dot{u}_{s}^{t}\right\}+\left[K_{s s}\right]\left\{u_{s}^{t}\right\}=-\left[M_{s g}\right]\left\{\ddot{u}_{g}\right\}-\left[C_{s g}\right]\left\{\dot{u}_{g}\right\}-\left[K_{s g u_{g}}\right]\left\{u_{g}\right\} .
$$

The vector of total displacements of the structure $\left\{u_{s}^{t}\right\}$ (as well as vectors of total velocities and accelerations) consists of two parts, i.e.: $\left\{u_{s}^{d}\right\}$ - the dynamic component and $\left\{u_{s}^{p}\right\}$ - the quasi-static component. Hence, the vector of total displacements can be quantified as follows:

$$
\left\{u^{t}\right\}=\left\{\begin{array}{c}
u_{s}^{d} \\
0
\end{array}\right\}+\left\{\begin{array}{l}
u_{s}^{p} \\
u_{g}
\end{array}\right\}
$$

The quasi-static component is expressed by an equation (4):

$$
\left\{u_{s}^{p}\right\}=[R]\left\{u_{g}\right\}
$$

where: $[R]-$ a transformation matrix which is expressed with the formula:

$$
[R]=-\left[K_{s S}^{-1}\right]\left[K_{s g}\right] .
$$

After including equation (3) Eq. (2) becomes equivalent to:

$$
\begin{aligned}
& {\left[M_{s s}\right]\left\{\ddot{u}_{s}^{d}\right\}+\left[C_{s s}\right]\left\{\dot{u}_{s}^{d}\right\}+\left[K_{s s}\right]\left\{u_{s}^{d}\right\}} \\
& =\left(\left[M_{s s}\right]\left[K_{s s}^{-1}\right]\left[K_{s g}\right]-\left[M_{s g}\right]\right)\left\{\ddot{u}_{g}\right\}+\left(\left[C_{s s}\right]\left[K_{s s}^{-1}\right]\left[K_{s g}\right]-\left[C_{s g}\right]\right)\left\{\dot{u}_{g}\right\} .
\end{aligned}
$$

EUROCODE 8 ([5]) allows for skipping the second element of the right hand side of Eq. (6), especially in the case of the Rayleigh stiffness-proportional model of damping. Taking into account formula (5), which describes the transformation matrix $[R]$, the following equation of motion of a structure under kinematic excitation can be formulated:

$$
\left[M_{s s}\right]\left\{\ddot{u}_{s}^{d}\right\}+\left[C_{s s}\right]\left\{\dot{u}_{s}^{d}\right\}+\left[K_{s S}\right]\left\{u_{s}^{d}\right\}=\left(-\left[M_{s s}\right][R]-\left[M_{s g}\right]\right)\left\{\ddot{u}_{g}\right\} .
$$

Since the dynamic response of a structure to kinematic excitation is obtained by numerical integration of Eq. (7), it depends on the ground accelerations vector $\left\{\ddot{u}_{g}\right\}$. The individual components of this vector represent time histories of the ground accelerations at particular supports of the structure. However, in seismic regions, time histories of accelerations are usually registered by a seismological station at one control point only. So, if non-uniform kinematic excitation is intended in calculations of a multiple-support structure, application 
of Eq. (7) requires additionally an assumption of a model of excitation. The main factors which affected the irregularity of kinematic excitation are: wave passage effect, incoherence effect, local soil effects and attenuation effect [4]. The idea of the formulation of the mathematical model for the spatially varying ground motion is based on the generating, from the registered seismic data, the time histories of kinematic loadings for the next supports of the structure. The most important assumption of the studied model of kinematic excitation was finite velocity of the seismic wave and attenuation effect. However, according to the nature of the seismic waves, the frequency structure of the registered data during in situ test was also studied.

\section{Concepts of investigation}

In Figure 1a the cable-stayed footbridge which was examined in the delivered work is presented. The structure is located in Czestochowa (Poland) and consists of two spans $(21.10 \mathrm{~m}$ and $25.80 \mathrm{~m})$. The total theoretical length of the footbridge is equal to $46.90 \mathrm{~m}$. The purpose of the structure is to conduct pedestrians and cyclists over the national expressway DK-1. The footbridge dynamic properties experimental and numerical assessment is presented in the work [6,7]. In Table 1 the dynamic characteristics of the structure are delivered. The FE model of the footbridge was validated since the experimental modal model was compared with the results obtained due to numerical procedures (see Tab. 1).

The general concept of numerical seismic assessment is presented in Figure 1b. As stated, the study was completed with two calculation approaches, i.e. with uniform as well as nonuniform kinematic excitation. For the uniform kinematic excitation recorded acceleration time-histories were used as loading applied to the footbridge supports. For the non-uniform kinematic excitation case the recorded and artificial acceleration time-histories were used. The artificial acceleration time-histories were extracted from the recorded signals. The wave passage effect was considered since the finite velocity of the seismic wave was assumed. Regarding to LGCD and USCB, the attenuation effect was taken into account as well [4].

a)

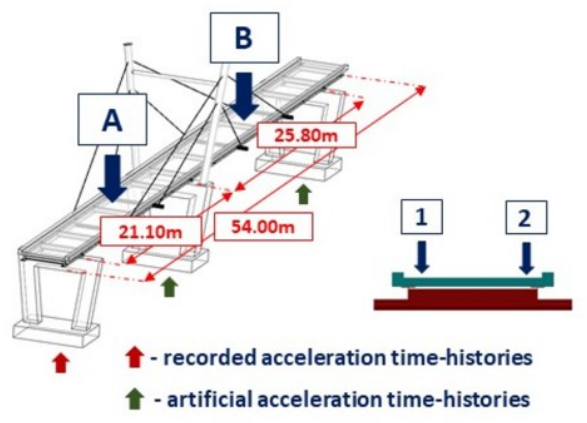

b)

\begin{tabular}{|l|}
\hline FOOTBRIDGE UNDER SEISMIC EXCITATION \\
\hline \begin{tabular}{|c|}
\hline $\begin{array}{c}\text { uniform kinematic } \\
\text { excitation }\end{array}$ \\
$\begin{array}{c}\text { non-uniform kinematic } \\
\text { excitation } \\
\text { (wave passage effect) }\end{array}$ \\
\hline SEISMIC ASSESMENT OF A FOOTBRIDGE \\
\hline
\end{tabular}
\end{tabular}

Fig. 1. (a) Structural layout of the footbridge, (b) general concept of the investigation

Table 1. Dynamic characteristics of the footbridge [6].

\begin{tabular}{|c|c|c|c|c|c|}
\hline \multirow{2}{*}{ Vibration mode (i) } & \multicolumn{2}{|c|}{ Frequency [Hz] } & \multirow{2}{*}{$\begin{array}{c}\text { Differences } \\
{[\%]}\end{array}$} & \multirow{2}{*}{$\begin{array}{c}M A C_{i i} \\
{[-]}\end{array}$} & \multirow{2}{*}{$\begin{array}{c}\text { Logarithmic } \\
\text { decrement } \delta[-]\end{array}$} \\
\hline & $F_{F E}$ & $f_{\text {exp }}$ & & & \\
\hline 1 & 2.71 & 2.76 & 1.81 & 0.99 & 0.086 \\
\hline 2 & 5.19 & 4.91 & 5.70 & 0.86 & 0.060 \\
\hline 3 & 6.32 & 6.08 & 3.95 & 0.95 & 0.056 \\
\hline
\end{tabular}


Figures 2 and 3 present main components of a representative mining shocks registered in Poland. The kinematic loading was applied in three directions $\left(a_{x}, a_{y}\right.$ and $\left.a_{z}\right)$ for both cases of mining shocks. The energy of the tremor in the LGCD was about $5 \cdot 10^{7} \mathrm{~J}$ and the energy of the tremor registered in the USCB region was about $1 \cdot 10^{7} \mathrm{~J}$, respectively. It must be pointed out that the energy of seismic event from LGCD region was 5 times bigger than the energy of the shock recorded in the USCB region.

a)

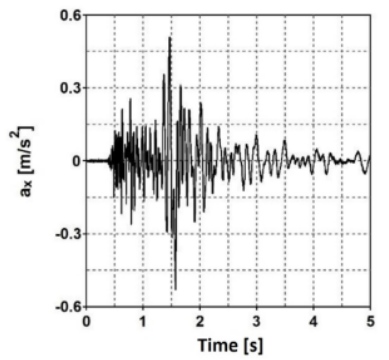

b)

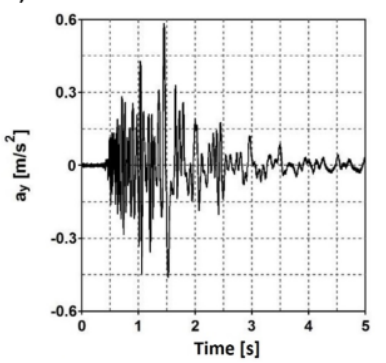

c)

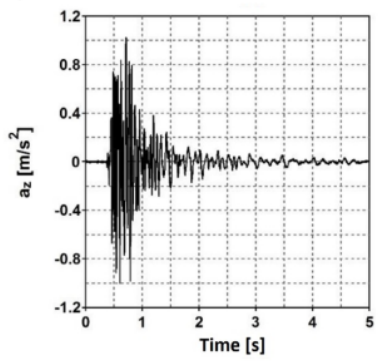

Fig. 2. Acceleration time-histories of ground motion registered in the LGCD region in three directions: (a) $a_{x}$, (b) $a_{y}$ and (c) $a_{z}$.

a)

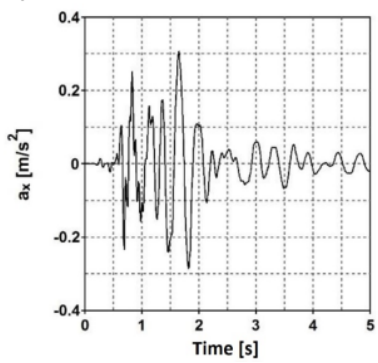

b)

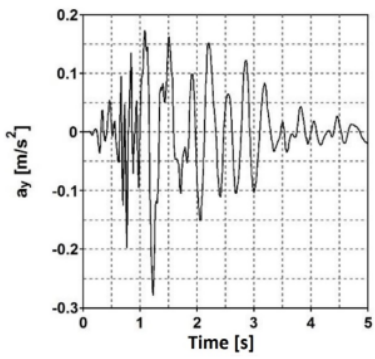

c)

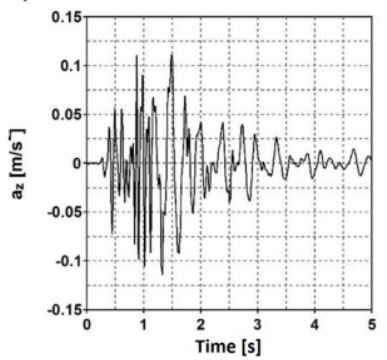

Fig. 3. Acceleration time-histories of ground motion registered in the USCB region in three directions: (a) $a_{x}$, (b) $a_{y}$ and (c) $a_{z}$.

The seismic performance of the structure to loading generated by investigated mining shocks (see Figs. 2 and 3) was completed using full-time history numerical procedures. It was prepared with the Hilber-Hughes-Taylor time integration algorithm provided in the ABAQUS/Standard for a direct step-by-step solution [7]. The step varied from $10^{-5}$ to $10^{-2} \mathrm{~s}$. The Rayleigh model of damping was applied for the numerical analysis. The coefficients of this damping model were calculated on the basis of experimental results for the first and the second mode shape (see Tab. 1) [6]. The mass proportional damping coefficient was equal to $\alpha=0.379$ and stiffness proportional damping coefficient was equal to $\beta=0.00022$, respectively.

\section{Results and discussion}

For the final assessment, the time-histories of the principal stresses at points A1, A2, B1, and B2 (see Fig. 1a) are presented (see Figs. 4 and 5). The maximum values of the principal stresses deepened on velocity of the seismic wave are also delivered in Figs. 6 and 7.

The time-histories of the principal stresses (see Figs. 4 and 5) were extracted for the uniform (black line) as well as non-uniform (red dotted line, velocity of the seismic wave equal to $200 \mathrm{~m} / \mathrm{s}$ ) kinematic excitation. From the study, it is clearly visible that uniform kinematic excitation provides more conservative results than non-uniform model. 
a)

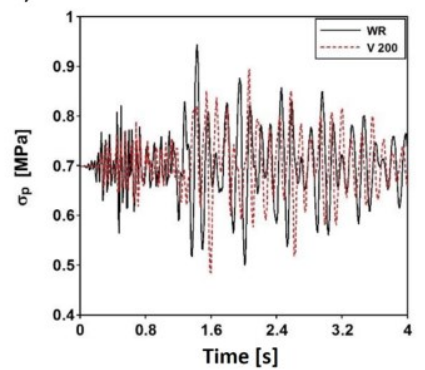

b)

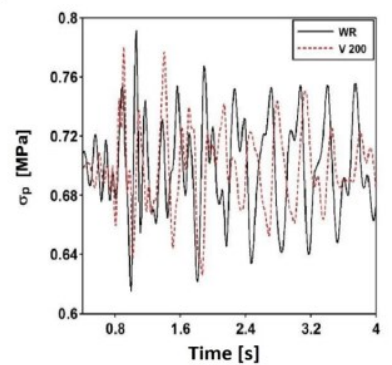

Fig. 4. Time-histories of the principal stresses at A1 control point: (a) LGCD and (b) USCB.

a)

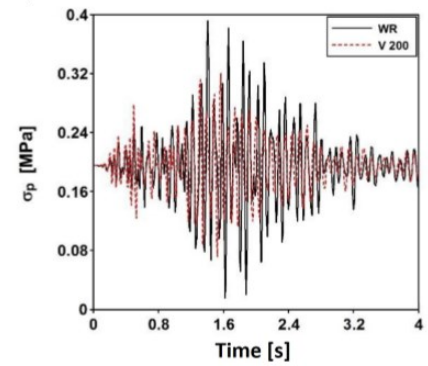

b)

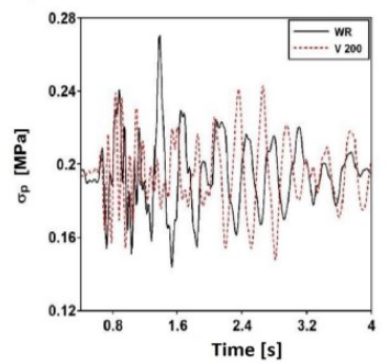

Fig. 5. Time-histories of the principal stresses at B1 control point: (a) LGCD and (b) USCB.

a)

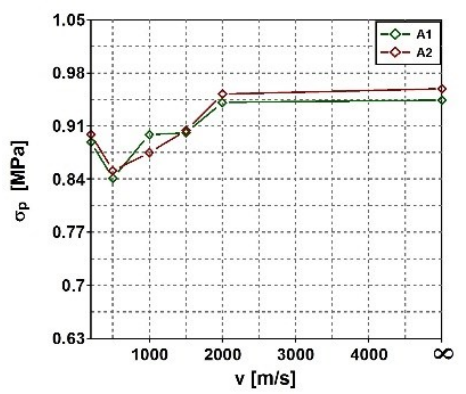

b)

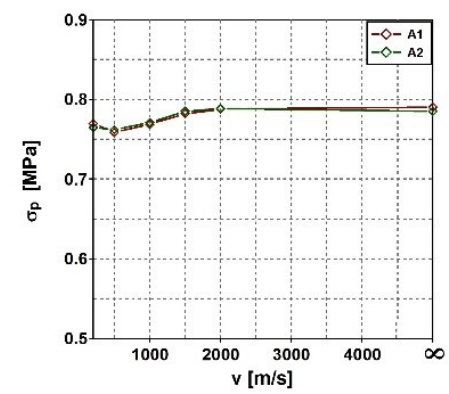

Fig. 6. Maximum values of the principal stresses at A1 and A2 control points deepened on velocity of the seismic wave: (a) LGCD and (b) USCB.

a)

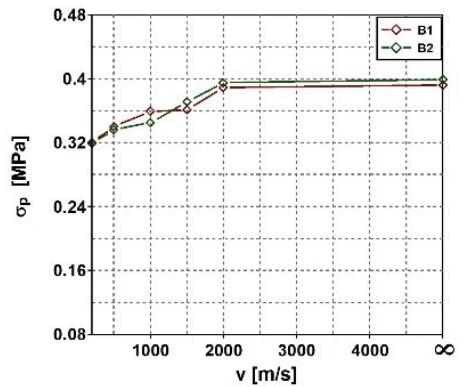

b)

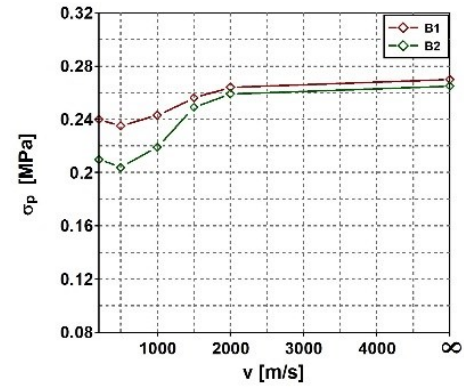

Fig. 7. Maximum values of the principal stresses at $\mathrm{B} 1$ and $\mathrm{B} 2$ control points deepened on velocity of the seismic wave: (a) LGCD and (b) USCB. 


\section{Conclusions}

The main aim of the presented study was the analysis of dynamic response of a cable-stayed footbridge to high-energy mining tremors. The numerical simulations were conducted with the non-uniform kinematic excitation as well as with the uniform kinematic excitation. From the investigation, the following main remarks can be provided:

- For seismic assessment of pedestrian bridges, it is reasonable to consider the type of their foundation, i.e. bridges are multiple-support structures,

- A series of numerical simulations were conducted to investigate the footbridge under mining tremor. The wave passage velocity was a variable factor for the non-uniform kinematic model of seismic excitation of the structure. The results demonstrated that the maximum values of principal stresses were achieved for the uniform kinematic model of seismic excitation.

\section{References}

1. E. Maciag, K. Kuzniar, T. Tatara, Earthq Spectra 6, 4 (2016)

2. L. Wotherspoon, A. Bradshaw, R. Green, C. Wood, A. Palermo, M. Cubrinovski, B. Bradley, 82 (6), 950-964 (2011)

3. A. Zerva, Probabilistic Engineering Mechanics 6, 212-221 (1991)

4. A. Zerva, Engineering Structures 16 (7), 534-546 (1994)

5. EN 1998-2: Eurocode 8: Design of structures for earthquake resistance - Part 2: Bridges, European Committee for Standardisation

6. I.J. Drygala, J.M. Dulinska, M. Wazowski, Procedia Engineer 193, 525-32 (2017)

7. I.J. Drygala, J.M. Dulinska, M. Wazowski, MATEC Web of Conferences 211, (2018)

8. ABAQUS Users' Manual v. 6.13. Dassault Systemes Simulia Corp., Providence, RI. (2013) 